\title{
Effect of Different Thermochemical Pretreatments on Fuel Quality of Sewage Sludge
}

\author{
Zhen-gang LIU* and Chao GAI \\ Research Center for Eco-Environmental Sciences, Chinese Academy of Sciences, 18 Shuangqing Road, Beijing 100085, PR \\ China \\ Email:zgliu@rcees.ac.cn
}

\begin{abstract}
Sewage sludge contains large amounts of energy and gasification of sewage sludge may be one of the promising sustainable approaches for hydrogen-rich syngas production from sewage sludge. However, raw sludge is unsuitable for direct gasification and thus pretreatment is necessary to improve its fuel quality prior to further thermal process. In this study, two types of the biochars, pyrochar from low temperature pyrolysis (LTP) and hydrochar from hydrothermal carbonization (HTC) were prepared, characterized and their gasification properties were experimentally evaluated. The results showed that the hydrochar was more hydrophobic than the pyrochar and its surface was rich of oxygen-containing functional groups, which enhanced the interactions between the carbon surface and hydrogen bonding as well as gasification reactivity of the hydrochar under identical conditions. Additionally, the porous structure on the surface of the hydrochar facilitated the pores better accessible for condensable hydrocarbon molecules and the hydrochar had improved gas production and gasification efficiency. This study demonstrates that the integration of HTC pretreatment and subsequent gasification has promising potential for hydrogen-rich syngas production from sewage sludge.
\end{abstract}

Keywords-sewge sludge; renewable energy; Hydogen; biomass

\section{INTRODUCTION}

As a by-product from municipal or industrial wastewater, sewage sludge is a kind of abundant biomass in developed and developing countries. Landfill, incineration and anaerobic digestion are traditional treatments for sewage sludge, which suffer from secondary pollution or long processing period [1]. Gasification appears to be a promising recycling approach for producing renewable hydrogen from sewage sludge in a shorter period of time [2-4]. However, one major disadvantage of the gasification of sewage sludge is that a dehydrating treatment is required for the gasification process. Because of the high moisture content as high as $90 \%$, the dewatering is a high energy-intensive consumption process and thus increases the cost of entire gasification [5].

Low temperature pyrolysis (LTP) is a typical pretreatment for upgrading waste biomass to solid fuels (pyrochar) [6,7]. It can convert biomass feedstock into pyrochar under an inert atmosphere with low heating rate. The pyrochar has improved physical and chemical characteristics, and it has been extensively used for soil amendment, wastewater pollution remediation, carbon sequestration and bioenergy production.Hydrothermal processing is one of important conversion techniques, which can enhance the transformation of biomass to fuels and chemical feedstocks in a water-rich phase at mild temperatures $\left(180-500{ }^{\circ} \mathrm{C}\right)$ and at sufficient pressures $[8,9]$. It offers several potential advantages in terms of high conversion efficiency, high throughputs, and the ability to use diverse feedstock without drying process $[10,11]$. In terms of the gasification of hydrochar derived from HTC, Álvarez-Murillo et al. [12] studied the steam gasification characteristics of the hydrochar derived from olive stone as a representative of lignocellulosic biomass. It was observed that the hydrochar modified the gas profiles during the gasification, improving $\mathrm{H}_{2}$ and $\mathrm{CO}$ production as well as the heating value. Erlach et al.[13] concluded that pretreating the lingocellulosic biomass with HTC produced a hydrochar that was better suited for entrained flow gasification than raw biomass. Escala et al. [14] reported that conducting HTC and drying the hydrochar have energetic advantages compared with drying the sewage sludge for thermal disposal treatment. These studies verified the improved gasification behavior of lignocellulosic biomass after the hydrothermal pretreatment. Different from lignocellulosic biomass (mainly composed of biopolymers cellulose, hemicellulose and lignin), the main composition of sewage sludge is protein and lipid. Therefore, different gasification behaviors of hydrochar/pyrochar derived from sewage sludge is expected to that of the biochar from lignocellulosic biomass.

In the present study, the physicochemical properties of pyrochar and hydrochar from LTP and HTC of sewage sludge were characterized. The difference of gasification behavior between the two biochars was evaluated comparatively.

\section{EXPERIMENTAL}

\section{A. Material and Methods}

Sewage sludge was collected from a municipal sewage treatment plant in Beijing, China. Hydrochar and pyrochar of sewage sludge were prepared by a typical HTC process and $\mathrm{HTC}$ at same temperature $220^{\circ} \mathrm{C}$. The detailed process can be found elsewhere [15]. The pyrochar and hydrochar derived from sewage sludge were both ground into powders 
less than $0.5 \mathrm{~mm}$ for the characterization and subsequent steam gasification experiments.

\section{B. Biochars Characterization}

Volatile matter and ash contents were determined following standard ASTM D3175-07 and ASTM D3174-12. Elemental analysis (C, H, N and S) was conducted on an elemental analyzer (CE-440, Exeter Analytical Inc., North Chelmsfor, MA). The higher heating value (HHV) of the raw sludge, pyrochar and hydrochar were determined by a bomb calorimeter (Model 1281, Parr Instrument Co., USA). The absolute contents of the metals were determined by Inductively Coupled Plasma Optical Emission Spectroscopy (ICP-OES). A scanning electron microscope (SEM, HR-FESEM SU8020, HITACHI, Japan) was applied to observe the surface morphologies. Fourier Transform Infrared Spectroscopy (FTIR, Thermo Nicolet Nexus 670, USA) was used to characterize surface functional groups of the samples.

\section{Steam Gasification Experiments}

Steam gasification of the pyrochar and hydrochar was carried out in a laboratory-scale fixed-bed reactor system. The main gas composition $\left(\mathrm{H}_{2}, \mathrm{CH}_{4}, \mathrm{CO}, \mathrm{CO}_{2}\right)$ was analyzed using a gas chromatograph (GC 3420A) equipped with a thermal conductivity detector (TCD) and two columns 5A and GDX-104.

\section{RESULTS AND DISCUSSION}

TABLE 1. UltiMATE AND PROXIMATE ANALYSIS OF RAW SLUDGE, THE PYROCHAR AND THE HYDROCHAR.

\begin{tabular}{|r|r|r|r|}
\hline Strain & Sewage sludge & Pyrochar & Hydrochar \\
\hline \multicolumn{4}{|c|}{ proximate analyses (\%, dry basis) } \\
\hline FC & 11.46 & 13.71 & 15.68 \\
\hline VM & 57.78 & 49.01 & 31.74 \\
\hline Ash & 30.76 & 37.28 & 52.58 \\
\hline \multicolumn{4}{|c|}{ ultimate analyses (\%, dry ash free basis) } \\
\hline C & 33.98 & 39.36 & 43.58 \\
\hline H & 6.02 & 4.37 & 4.79 \\
\hline N & 6.24 & 7.97 & 9.52 \\
\hline O* & 52.84 & 45.58 & 42.63 \\
\hline S & 0.92 & 1.17 & 1.03 \\
\hline
\end{tabular}

*By difference

Table 1 showed the elemental and proximate analysis results. Elemental analysis showed that the carbon content of the pyrochar and hydrochar was higher than that of the raw sludge. The oxygen content of the hydrochar was lower than that of the pyrochar and raw sludge. Proximate analysis illustrated that compared to raw sludge, the amounts of volatile matter (VM) of the pyrochar and hydrochar both decreased while the contents of fixed carbon (FC) and ash both increased. It is mainly attributed to the devolatilization of VM and polymerization during the pyrolysis/hydrothermal process. For the pyrochar and hydrochar, the loss of VM was higher than the increased FC, indicating that $\mathrm{VM}$ was converted to other gaseous products (e.g. $\mathrm{CO}_{2}$ ) or liquid. The higher heating value of the hydrochar was also higher than that of the pyrochar and raw sludge. The higher heating value of sewage sludge was increased after the HTC treatment, verifying that HTC is a suitable treatment for upgrading the fuel properties of biomass feedstock. Fig. 1 also showed that the contents of metals in the raw sludge and two biochars were different. The main metal constituents of the raw sludge were nickel (Ni), iron (Fe), alkali and alkaline earth metallic species (AAEMs) in terms of potassium $(\mathrm{K})$, sodium $(\mathrm{Na})$, calcium (Ca) and magnesium $(\mathrm{Mg})$. Besides, these materials contain a certain content of silicon ( $\mathrm{Si}$ ) and aluminum (Al). The contents of $\mathrm{Ni}$ and $\mathrm{Fe}$ for the hydrochar were higher than that of the pyrochar. The high contents of AAEMs in biochar are also known to act as catalysts during the gasification process.

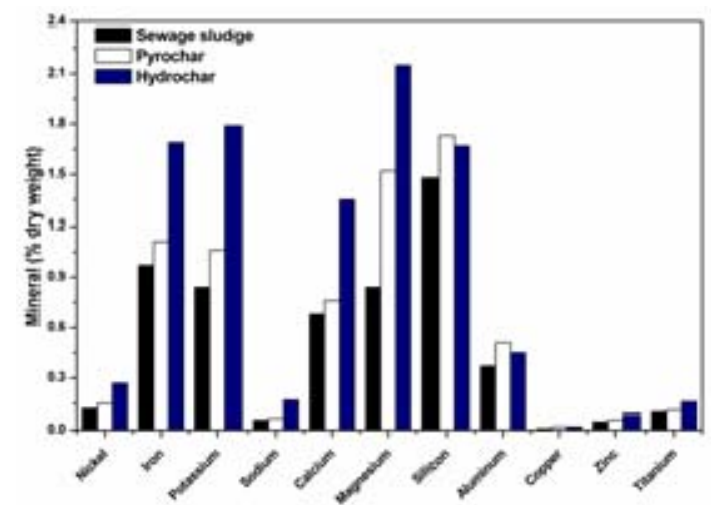

Fig. 1 Metal content in raw sewage sludge, pyrochar and hydrochar.

SEM images of raw sludge, pyrochar and hydrochar were compared in Fig. 2. The raw sludge and pyrochar were both relatively smooth structured while the microstructure of the hydrochar was quite different. Porous and disintegrated structures can be seen in the hydrochar due to the devolatilization/decompostion of organic component of sewage sludge during the hydrothermal carbonization and different forms can be observed in terms of cracks and trenches with small microspheres. Micrometer sized particle dispersions with different forms in terms of honeycombs, fluffy sponges, or spherically shaped particles were also observed, which mainly originates from carbohydrates [16].

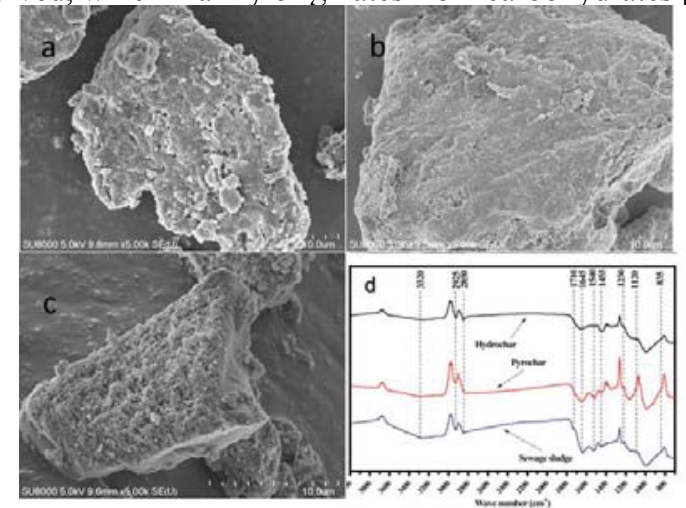

Fig.2 SEM images and FT-IR spectra of raw sludge, pyrochar and hydrochar.

The FTIR spectra for the raw sludge and two biochars were presented in Fig. 2d. The absorbance peaks at $3320 \mathrm{~cm}^{-}$ 
1 represent the $\mathrm{O}-\mathrm{H}$ stretching vibration in hydroxyl or carboxyl functional groups. Compared to the raw sludge, this peak became less intense for the pyrochar and hydrochar, which was due to the dehydration process. It is consistent with the decreased hydrogen content for the pyrochar and hydrochar. Absorbance peak between 3000 and $2800 \mathrm{~cm}^{-1}$ is ascribed to aliphatic carbon $-\mathrm{CHx}$ stretching vibration in terms of asymmetric $\left(2925 \mathrm{~cm}^{-1}\right)$ and symmetric $\left(2850 \mathrm{~cm}^{-1}\right)$ -C-H stretching of methylene groups. As for these two peaks, no significant difference was observed for the raw sludge and hydrochar, whereas this peak was increased for the pyrochar. The peaks at $1710 \mathrm{~cm}^{-1}$ and $1120 \mathrm{~cm}^{-1}$ are attributed to $\mathrm{C}=\mathrm{O}$ and $\mathrm{C}-\mathrm{O}$ stretching vibrations of ester bonds, and a decrease of the two peaks was observed for the pyrochar and hydrochar compared to the raw sludge. It verified the speculation of occurrence of proteolysis during the HTC process mentioned above. The observation in FTIR spectra confirmed that the carboxyl and carbonyl groups were rapidly degraded above $150^{\circ} \mathrm{C}$ [17]. The band at 1645 $\mathrm{cm}^{-1}$ is ascribed to the stretching vibration of $-\mathrm{C}=\mathrm{O}$ in ketone groups. The band at $1540 \mathrm{~cm}^{-1}$ is assigned to the asymmetric stretching of $-\mathrm{C}=\mathrm{O}$ in carboxylic groups. As for the two bands, no prominent fluctuation was observed for the raw sludge and pyrochar, while a significant decrease was observed in that of the hydrochar. It verified the occurrence of decarboxylation in HTC process. Compared to the raw sludge and pyrochar, $\mathrm{N}-\mathrm{H}$ bending $\left(1575-1525 \mathrm{~cm}^{-1}\right)$ was observed in hydrochar, indicating the presence of amide compounds. Compared to the raw sludge, the pyrochar and hydrochar both showed a strong absorbance at $1455 \mathrm{~cm}^{-1}$, especially for the hydrochar, which is associated with the $\mathrm{C}=\mathrm{C}$ stretching in aromatic ring carbons. The peaks at 1230 $\mathrm{cm}-1$ and $835 \mathrm{~cm}^{-1}$ were also observed in the spectra of pyrochar and hydrochar, which are ascribed to the aromatic $\mathrm{C}-\mathrm{H}$ out-of-plane bending vibration, aromatic $\mathrm{CO}-$ and phenolic $-\mathrm{OH}$ stretching, respectively. The three peaks suggest that aromatization was occurred during the thermal/hydrothermal treatments at the selected temperature. Overall, the oxygenated surface functional groups for the pyrochar and hydrochar were both decreased, which is consistent with the decrease in the oxygen content of the pyrochar and hydrochar. Aliphatic $\mathrm{C}-\mathrm{H}$ functional groups were dominated in the pyrochar while more aromatic $\mathrm{C}-\mathrm{H}$ functional groups were formed in the hydrochar. This confirms that the hydrochar is more hydrophobic than that of the pyrochar [17]. The sewage sludge derived pyrochar had a low degree of aromaticity. McBeath et al. [18] analyzed cross-polarization and direct polarization spectra of pyrochar derived from chestnut wood. It was concluded that the aromaticity of pyrochar rapidly increases when temperature is above $400{ }^{\circ} \mathrm{C}$. It was also reported that the pyrochar produced around $350^{\circ} \mathrm{C}$ was mainly dominated by aromatic (aryl) carbon with small fractions of alkyl-O and alkyl-C [17]. A further increase of temperature over $500{ }^{\circ} \mathrm{C}$ may result in a completely conversion of alkyl-O and alkyl-C to aryl carbon. Therefore, pretreatment temperature can significantly affect the aromatic character of the biochar.

Evolution of main composition of product gas $\left(\mathrm{N}_{2}\right.$ free and dry basis) in the steam gasification of the pyrochar and hydrochar was greatly affected by the temperature and S/B mass ratio (shown in Fig.3 and 4). The $\mathrm{H}_{2}$ concentration strongly increased with increasing temperature from 700 to $900{ }^{\circ} \mathrm{C}$ for the pyrochar and hydrochar, but showed some decrease when the temperature was further increased to 1000 ${ }^{\circ} \mathrm{C}$. The CO content was also found to increase continuously, while the $\mathrm{CO}_{2}$ and $\mathrm{CH}_{4}$ concentration decreased gradually. The higher temperature $\left(1000^{\circ} \mathrm{C}\right)$ yielding a relative low $\mathrm{H}_{2}$ concentration is mainly due to the thermodynamic equilibrium limitations of endothermic water-gas shift (WGS) reaction in the steam gasification process. Based on WGS, an enhanced hydrogen concentration can be accomplished if $\mathrm{CO}_{2}$ is removed. As for the effect of $\mathrm{S} / \mathrm{B}$ mass ratio on the evolution of the gas product composition, the concentrations of $\mathrm{H}_{2}$ and $\mathrm{CO}_{2}$ for the pyrochar and hydrochar were increased first and then decreased while the content of $\mathrm{CO}$ and $\mathrm{CH}_{4}$ declined slightly with the increment of $\mathrm{S} / \mathrm{B}$ ratio from 0.5 to 2.0. The decrease in $\mathrm{CH}_{4}$ concentration, however, was very slightly. A high S/B ratio favors WGS reaction for $\mathrm{H} 2$ and $\mathrm{CO}_{2}$ formation, and promotes the steam reforming of condensable hydrocarbons (tars) with high molecular weight. However, an excessive S/B ratio was observed to decrease the $\mathrm{H}_{2}$ concentration for the two biochars. It is probably due to the short residence time of the product gas with the increment of steam flow rate, result in a decrease of time in reactions between the steam and hydrocarbons. Therefore, the optimum ratio of S/B for maximizing $\mathrm{H}_{2}$ concentration of the pyrochar and hydrochar was 1.5 and 1.0, respectively. Additionally, a proper $\mathrm{S} / \mathrm{B}$ ratio can be determined for enhancing hydrogen production.

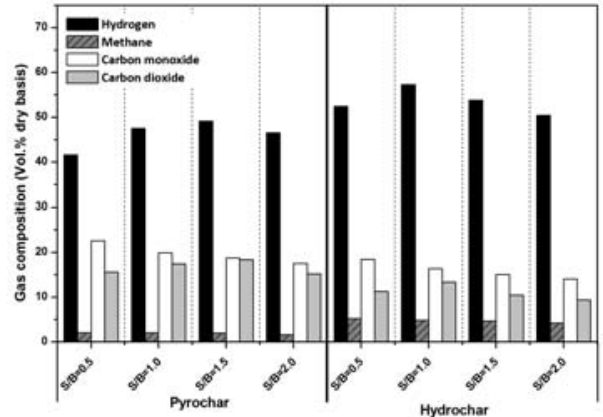

Fig.3. Effect of temperature on the main gas composition during the steam gasification of the pyrochar and hydrochar (Reaction conditions: $1 \mathrm{~atm}, \mathrm{~S} / \mathrm{B}$ mass ratio $=0.5$ )

The hydrogen yields for pyrochar and hydrochar were greatly enhanced with the increased temperature. Additionally, the hydrogen yield of gasification of hydrochar was always higher than that of pyrochar by $10-40 \%$ under identical gasification conditions. The maximum hydrogen yield (76.70 $\mathrm{g} \mathrm{H}_{2} / \mathrm{kg}$ biochar) for hydrochar was achieved at an $\mathrm{S} / \mathrm{B}$ ratio of 1.0 under the gasification temperature of $1050^{\circ} \mathrm{C}$. This yield is comparable to that of steam gasification of pine sawdust combined with porous ceramic reforming of syngas and tar (79.91 $\mathrm{g} \mathrm{H}_{2} / \mathrm{kg}$ biomass). 
The LHV of the pyrochar and hydrochar were also significantly affected by the reaction temperature and S/B mass ratio. The optimum temperature for maximizing LHV for the pyrochar $\left(8.32 \mathrm{MJ} / \mathrm{Nm}^{3}\right)$ and hydrochar $(10.55$ $\mathrm{MJ} / \mathrm{Nm}^{3}$ ) were both $950^{\circ} \mathrm{C}$, while at the temperature of 1050 ${ }^{\circ} \mathrm{C}$, the optimum $\mathrm{S} / \mathrm{B}$ mass ratio for the pyrochar (8.39 $\left.\mathrm{MJ} / \mathrm{Nm}^{3}\right)$ and hydrochar $\left(9.96 \mathrm{MJ} / \mathrm{Nm}^{3}\right)$ was both 1.0 . LHV of the product gas is dependent on the gas composition, especially for $\mathrm{H}_{2}$ because the main combustible gas composition is hydrogen. Dissimilar with LHV, the gasification efficiency for the pyrochar and hydrochar were observed to be increased continuously as a function of temperature. It should be due to the favored thermal decomposition of condensable hydrocarbons at high temperatures. However, an excessive S/B mass ratio (i.e., higher than 1.0) was observed to decrease gasification efficiency for the two biochars. It may be explained by the fact that the residence time of reaction intermediates is shortened due to the increased steam flow rate, render an inhibition of steam evolved reactions. It should be noted that the gasification efficiency at a higher S/B mass ratio (i.e., higher than 1.0) for the two biochars were both higher than that of lower temperatures (i.e., lower than $1050^{\circ} \mathrm{C}$ ). According to Palumbo et al. [19], increasing temperature would reduce the effect of kinetic limitation and promote the attainment of reaction equilibrium for gaseous products even for short residence time. Overall, compared to the raw sludge and pyrochar, the hydrothermally treated sewage sludge had improved gasification characteristics in terms of in terms of hydrogen yield, LHV and gasification efficiency.

An index of energy recovery efficiency (ERE) was used to evaluate the effect of two different pretreatments on the entire energy balance. A EREi $i_{\text {Total }}$ of 1 means that the total energy consumption during the HTC/LTP pretreatment combined with subsequent gasification is equal to the energy evolved in the product gas. Under identical condition, the $\mathrm{EREi}_{\text {Total }}$ of LTP was higher than that of HTC, implying that combining LTP and gasification is a more energy-saving approach for hydrogen-rich syngas production, compared with that of HTC-gasification method. Nevertheless, under identical condition, the HTC-gasification method can produce a syngas with higher yield and concentration of hydrogen. And the EREi Total of HTC-gasification method was higher than 1, implying that the total energy consumption during the HTC pretreatment combined with subsequent gasification is lower than the energy evolved in the product gas.

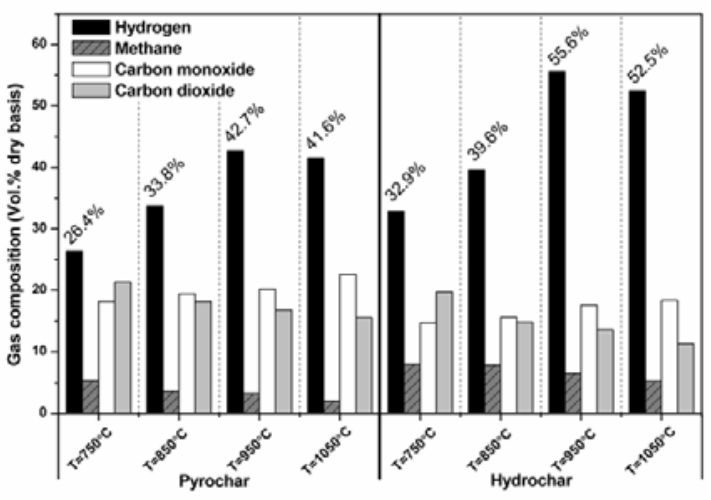

Fig.4 Effect of S/B mass ratio on the evolution of the main gas composition during the steam gasification of the pyrochar and hydrochar (Reaction conditions: $1 \mathrm{~atm}, \mathrm{~T}=1050{ }^{\circ} \mathrm{C}$ ).

\section{CONCLUSIONS}

The pyrochar derived from the low temperature pyrolysis of sewage sludge was rich in aliphatic $\mathrm{C}-\mathrm{H}$ functional groups while more aromatic $\mathrm{C}-\mathrm{H}$ functional groups were presented in the hydrochar. Compared to the LTP-gasification method, the HTC pretreatment combined with subsequent gasification had a lower energy recovery efficiency of the whole process. However, the steam gasification of the hydrochar exhibited higher hydrogen concentration and yield as well as higher heating value, and gasification efficiency. The present study demonstrated that hydrothermal carbonization is a more effective pretreatment for enhancing hydrogen production from sewage sludge via steam gasification.

\section{ACKNOWLEDGMENT}

The authors gratefully acknowledge financial support for Zhengang Liu from the "100 Talents" Program of the Chinese Academy of Sciences.

\section{REFERENCES}

[1] Cieślik BM, Namieśnik J, Konieczka P. Review of sewage sludge management: standards, regulations and analytical methods. J Clean Prod. 2015; 90: 1-15.

[2] Reddy SN, Nanda S, Dalai AK, Kozinski JA. Supercritical water gasification of biomass for hydrogen production. Int J Hydrogen Energ 2014; 39: 6912-6926.

[3] Hu M, Guo D, Ma C, Hu Z, Zhang B, Xiao B, et al. Hydrogen-rich gas production by the gasification of wet MSW (municipal solid waste) coupled with carbon dioxide capture. Energy 2015; 90: 857863.

[4] Choi YK, Cho MH, Kim JS. Steam/oxygen gasification of dried sewage sludge in a two-stage gasifier: Effects of the steam to fuel ratio and ash of the activated carbon on the production of hydrogen and tar removal. Energy 2015; 91: 160-167.

[5] Manara P, Zabaniotou A. Towards sewage sludge based biofuels via thermochemical conversion-A review. Renew Sust Energ Rev 2012; 16: $2566-1582$

[6] Tian K, Liu WJ, Qian TT, Jiang H, Yu HQ. Investigation on the evolution of N-containing organic compounds during pyrolysis of sewage sludge. Environ. Sci. Technol. 2014, 48, 10888-10896. 
[7] Liu S, Wei M, Qiao Y, Yang Z, Gui B, Yu Y, Xu M. Release of organic sulfur as sulfur-containing gases during low temperature pyrolysis of sewage sludge. P Combust Inst 2015; 35: 2767-2775.

[8] Toor SS, Rosendahl L, Rudolf A. Hydrothermal liquefaction of biomass: A review of subcritical water technologies. Energy $2011 ; 36$ : 2328-2342.

[9] Peng C, Zhai Y, Zhu Y, Xu B, Wang T, Li C, Zeng G. Production of char from sewage sludge employing hydrothermal carbonization: Char properties, combustion behavior and thermal characteristics. Fuel 2016, 176: 110-118.

[10] Gai C, Li Y, Peng N, Fan A, Liu Z. Co-liquefaction of microalgae and lignocellulosic biomass in subcritical water. Bioresour Technol 2015; 185: 240-245.

[11] Kruse A, Funke A, Titirici MM. Hydrothermal conversion of biomass to fuels and energetic materials. Curr Opin Chem Biol 2013; 17: 515521.

[12] Álvarez-Murillo A, Ledesma B, Román S, Sabio E, Gañán J. Biomass pyrolysis toward hydrocarbonization. Influence on subsequent steam gasification processes. J Anal Appl Pyrol 2015; 113: 380-389.

[13] Erlach B, Harder B, Tsatsaronis G. Combined hydrothermal carbonization and gasification of biomass with carbon capture. Energy 2012; 45: 329-338.
[14] Escala M, Zumbühl T, Koller C, Junge R, Krebs R. Hydrothermal carbonization as an energy-efficient alternative to established drying technologies for sewage sludge: A feasibility study on a laboratory scale. Energy Fuel 2013; 27: 454-460.

[15] Gai C, Chen M, Liu T, Peng N, Liu Z. Gasification characteristics of hydrochar and pyrochar derived from sewage sludge. Energy 2016b; 113: 957-965.

[16] Titirici MM, Antonietti M, Baccile N. Hydrothermal carbon from biomass: a comparison of the local structure from poly-to monosaccharides and pentoses/hexoses. Green Chem 2008; 10: 12041212 .

[17] Kambo HS, Dutta A. A comparative review of biochar and hydrochar in terms of production, physico-chemical properties and applications. Renew Sust Energ Rev 2015; 45: 359-378.

[18] McBeath AV, Smernik RJ, Schneider MPW, Schmidt MWI, Plant EL. Determination of the aromaticity and the degree of aromatic condensation of a thermosequence of wood charcoal using NMR. Org Geochem 2011; 42: 1194-1202.

[19] Palumbo AW, Sorli JC, Weimer AW. High temperature thermochemical processing of biomass and methane for high conversion and selectivity to H2-enriched syngas. Appl Energy 2015; 157: $13-24$. 